Article

\title{
Tomographic Environmental Sections for Environmental Mitigation Devices in Historical Centers ${ }^{\dagger}$
}

\section{Roberta Cocci Grifoni *, Maria Federica Ottone and Enrico Prenna}

SAD—School of Architecture and Design “Eduardo Vittoria”, University of Camerino, Viale della Rimembranza, 63100 Ascoli Piceno, Italy; mariafederica.ottone@unicam.it (M.F.O.); enrico.prenna@unicam.it (E.P.)

* Correspondence: roberta.coccigrifoni@unicam.it; Tel.: +39-0737424059

+ This is an expanded version of a conference paper: Prenna, E.; Ottone, M.F.; Cocci Grifoni, R. The tomographic environmental sections for environmental mitigation devices in historical centers. In Proceedings of the IEEE 16th International Conference on Environment and Electrical Engineering (EEEIC), Florence, Italy, 6-8 June 2016.

Academic Editor: Chi-Ming Lai

Received: 23 December 2016; Accepted: 27 February 2017; Published: 11 March 2017

\begin{abstract}
Urban heat waves and the overall growing trend in the annual global temperature underline the importance of urban/architectural resilience and the need to reduce energy consumption. By designing urban voids, it is possible to create thermodynamic buffers, i.e., bubbles of controlled atmosphere that act as mediators between the natural and built environments, between the human body and the surrounding air, between meteorology and physiology (meteorological architecture). Multiple small actions in the urban fabric's open spaces, such as replacing dark pavements or inserting vegetation and green spaces, are intended to improve outdoor comfort conditions and therefore the resilience of the city itself. This not only benefits the place's quality, which is intrinsic to the new project, but also the insulating capacity of buildings, which are relieved of an external heat load. The design emphasis therefore changes from solid structures to the climate and weather conditions, which are invisible but perceivable. To design and control these constructed atmopheres, tomographic sections processed with computational fluid dynamics software (tomographic environmental section, TENS) becomes necessary. It allows the effects of an extreme event on an outdoor environment to be evaluated in order to establish the appropriate (adaptive) climate mitigation devices, especially in historical centers where energy retrofits are often discouraged. By fixing boundary conditions after a local intervention, the virtual environment can be simulated and then "sliced" to analyze initial values and verify the design improvements.
\end{abstract}

Keywords: tomographic environmental section (TENS) method; global warming; heat waves; urban acupuncture; computational fluid dynamics (CFD); outdoor comfort

\section{Introduction}

In recent years, the increase in temperature caused by global warming has been following a worrying trend in which the number of months characterized by record high temperatures continues to increase [1]. The latest data from National Aeronautics and Space Administration's Goddard Institute for Space Studies (GISS) in New York, NY, USA, show that August 2016 was the hottest month since 1880, the first year that global temperature measurements with modern monitoring methods were made. Data regarding worldwide temperatures before that time are not considered reliable because a network of meteorological stations spread around the world did not yet exist.

In a note published on data.giss.nasa.gov, NASA scientists reveal an alarming trend. The cycle of seasonal temperatures usually reaches its peak in the month of July. However, both July and August 
2016 will be remembered as the hottest months ever recorded. Average global temperatures registered in August 2016 were $0.16{ }^{\circ} \mathrm{C}$ higher than the levels recorded in August 2014, one of the hottest years in climate history. With respect to the average temperature registered from 1951 to 1980, the temperature in August 2016 was $0.98^{\circ} \mathrm{C}$ higher. This alarming aspect of climate change should also be considered in light of the consistent growth of global energy consumption.

Forecasts from the International Energy Agency (IEA) indicate an increase in worldwide energy consumption-due to the increase in per-capita demand-of $60 \%$ over current consumption by 2030. Considering that $50 \%$ of people now live in urban areas-with some areas reaching $80 \%$-and considering a rate of growth in energy consumption to be $1.9 \%$ annually, urban energy consumption is expected to double with the current average rate of European growth [2]. This process of urbanization, combined with the potential impact of climate change induced by anthropic sources [1], provides new impetus for efforts to understand how forms, functions, and resources interact within urban environments. In fact, in some cities, per-capita energy consumption has seen an increase that is directly proportional to spatial growth [3]. Given the growing contribution of cities to climate-altering emissions [4], addressing global climate change on an urban level is very important, in that it guarantees greater efficiency of possible interventions. The local level, which is simultaneously part of the problem and part of the solution, therefore becomes the ideal starting point for point-like, local analyses that allow a real transition to be made towards a sustainable urban model capable of mitigating climate events. If appropriately related to each other, local climate change, the urban form, density, and morphology offer an opportunity to address climate questions locally, both in political strategies and in urban planning.

With these premises, this research proposes a methodological strategy based on point-like thermal fluid dynamic analysis defined starting with the theory of urban acupuncture [5]. In human acupuncture, a precise point is manipulated in order to heal the patient's body. Similarly, in urban design, an architect or planner should be able to determine the right location to provide enhancements to all parts of the city. To determine this location, it is important to know the causes of the city's illness. The term urban acupuncture was first used by Manuel de Sola-Morales in 2006 [5]. Using this concept, he tried to solve urban problems by inserting strategic architectural projects into the urban fabric. The concept of urban acupuncture refers to urban interventions that can be built in a short time and which spontaneously improve the surrounding environment.

Urban acupuncture represents the initial theory of a more "situational" approach, which began in the city of Curitiba, Brazil, when Jaime Lerner, an architect, urban planner, theorist, and politician became mayor in 1971. He developed this concept to explain and create a universal methodology obtained from real experience in urban management. It was then adopted in various forms by urban planners and architects such as Bernardo Secchi [6] (Porous City) and Renzo Piano [7] (urban mending), to mention the most well known. To Lerner, urban acupuncture also aims to cure energy flows in sick or painful sites by revitalizing the location (selected point) and its surrounding areas. Contemporary cities are not designed for human comfort, but for the circulation of cars, and an abundance of private rather than public spaces is provided. Many cities lost the element of health (healthy cities) when they began to arbitrarily modify public spaces, rivers, streets, and town squares.

The urban acupuncture approach is defined as a process of "inserting" micro-places, which, created in the context, generate macro-places; in the same way, inserting small comfort places can generate larger comfort places. Useful planning indications can be provided to mitigate the microclimate of spaces [8] by studying the thermal fluid dynamics of numerous transverse and longitudinal sections (tomographic environmental sections, TENSs [9]). Using repeated vertical cross-sections to study the microclimate conditions of the site, TENS is used to identify and analyze the interactions between open urban spaces and buildings. The microclimate of the site can therefore be adjusted by addressing the specifics of the individual places in relation to the structure of the urban settlement or landscape. Any computational fluid dynamics (CFD) tool may be used for thermographic analysis. To more easily understand the relationships between occupied and empty spaces in the 
built environment, two-dimensional horizontal and vertical images are used to produce 3D models regarding environmental and climate data.

This method was applied to several case studies dealing with the urban fabric on the edges of the historical center of the city of Ascoli Piceno in the Marche Region in Italy (Figure 1). The basic layout of the city center dates from the Roman era and is still visible today with its cardo and decumano, which defined the orthogonal urban structure. Just as this evidence is still visible today, subsequent eras also modified the historical center with respect to the type of buildings and materials of the time. It is possible, therefore, to identify characteristics shared with other historical towns of the same size, both in Italy and in Europe [10].

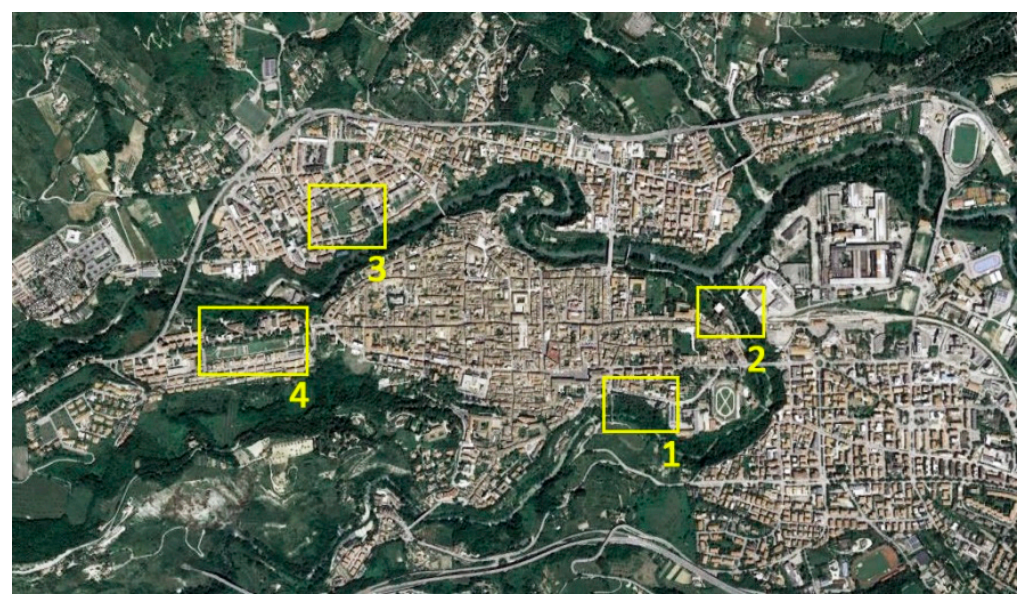

Figure 1. The city of Ascoli Piceno-Case studies: no. 1 Bus station, no. 2 Ex Società Impianti Materiali Elettrici (S.I.M.E.), no. 3 Porta Solestà, no. 4 Ex Tiro a Segno.

The starting point for environmental interventions in the historical fabric is therefore characterized by analyzing a typical building fabric composed of houses with towers, working-class neighborhoods, well-proportioned governmental buildings, churches, and noble palaces, and likewise by empty spaces such as large squares, public cloisters, porticoes, alleys, and main roads. The unique aspect of the center of Ascoli Piceno is the use of typical local materials, such as travertine, which was used over the centuries in different areas and ways, from building façades to the pavement in the squares.

Ultimately, these typological and material characteristics have a large effect on the urban microclimate [11]. While they favor shading, ventilation, and heat refraction, they are no longer sufficient to guarantee good thermal and humidity comfort. Moreover, they create a historical/cultural limit for more incisive interventions and renovations.

Over the years, the average temperature has also been increasing in Ascoli Piceno and in many historical towns in the Marche Region. In particular, the city of Ascoli Piceno is subject to the well-known urban heat island (UHI) effect, as can be seen in Figure 2.

To study this effect, the phenomenon was analyzed on the urban microscale [12]. The microscale is useful for verifying relationships between the urban form, roofing materials, and the UHI, with particular reference to green roofs, land permeability, and albedo of the materials.

The following urban factors particularly influence the microclimate on various scales: building orientation, surfaces, sky view factor (SVF), solar incidence, the materials used, and the form of the buildings. For example, where buildings are very close together (typical streets in the historical city center), temperatures are affected by the SVF whereby the building façades are heated more than other buildings on more open and ventilated streets, even if only a few tens of meters away. 


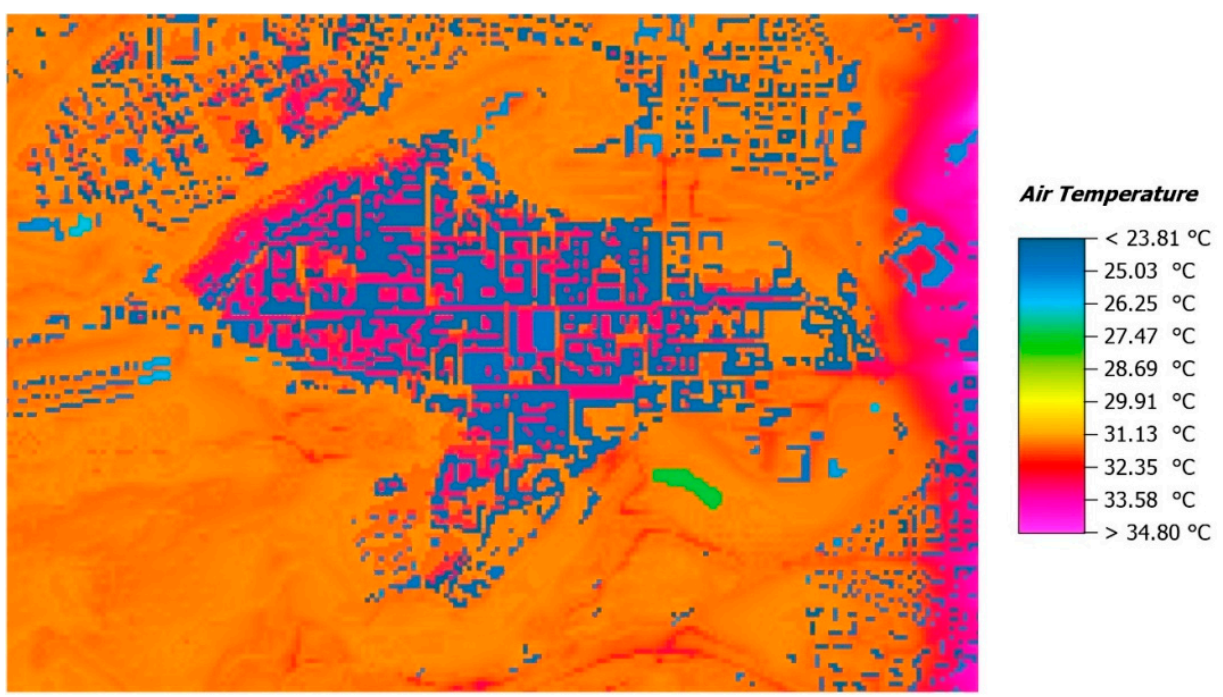

Figure 2. Urban heat island (UHI) in the city of Ascoli Piceno.

A recent study demonstrated how the urban microclimate influences the functions of the buildings in terms of thermal performance and how the urban form thereby influences the UHI effect [13]. The UHI, particularly in Italian cities, does not depend so much on human activities, that is, on the anthropogenic heat produced, but rather on the heat stored in urban surfaces (buildings, streets, parking areas) during the day, which is then released gradually throughout the night (Musco et al.) [14]. This effect generates a nocturnal heat island in that the heat released does not allow the city to cool as much as the surrounding rural areas. The complexity of the UHI effect is directly connected to the city-atmosphere relationship [14]. Just as the urban climate is affected by the atmospheric climate and its impacts on the population and infrastructures, the atmospheric climate is in turn affected by the urban climate [15].

Precisely in order to intervene in a calculated way with more certain results, the TENS method [9] was used to measure effective outdoor urban comfort and to size the case studies to maximize the sense of thermal well-being without altering the historical urban fabric. This method uses thermal fluid dynamic analysis in transverse sections on the layout of a virtual environment modeled on the basis of previous environmental surveys. It is therefore an appropriate tool to study the current situation and to immediately verify design proposals.

The particularity of the TENS method is clear: through direct comparison of the same section in the current state and the proposed state, the mitigation effects of the proposed device can be evaluated and corrected, thereby avoiding invasive, inefficient design solutions.

\section{Materials and Methods}

The TENS method requires experimental observations in the field using environmental surveying equipment or data from local weather stations in order to define the microclimate of each case study. These constitute the boundary conditions for the digital model and the different climate values to serve as a control sample. The collected data are then processed and used to create a 3D environmental model for each area identified. The climate conditions detected can thus be simulated with CFD software, verifying both the current state and the design proposal. In the end, tomographic rendering allows variations to be compared and checked, and whether improvements in the climate conditions and thermohygrometric comfort have been obtained. These are illustrated with plans and sections created by slicing the 3D environmental model (Figure 3).

This study was carried out using ENVI-met v. 4.0 software (a CFD tool, GmbH, Essen, Germany) to make a comparative analysis between the pre- and post-intervention state of the area [16]. The software uses an SVAT-type (soil, vegetation, atmosphere transfer) deterministic method of calculation for the 
small urban scale, and, through the use of thermal fluid dynamics equations, allows the behavior of a three-dimensional climate model to be simulated. With the built-in SPACE module in ENVI-met, a 3D model was developed to evaluate the fluid dynamics effects on the urban area of interest with a grid dimension of $250 \times 250 \times 30$ cells, $2 \mathrm{~m} \times 2 \mathrm{~m} \times 2 \mathrm{~m}(\mathrm{~d} x-\mathrm{d} y-\mathrm{d} z)$.
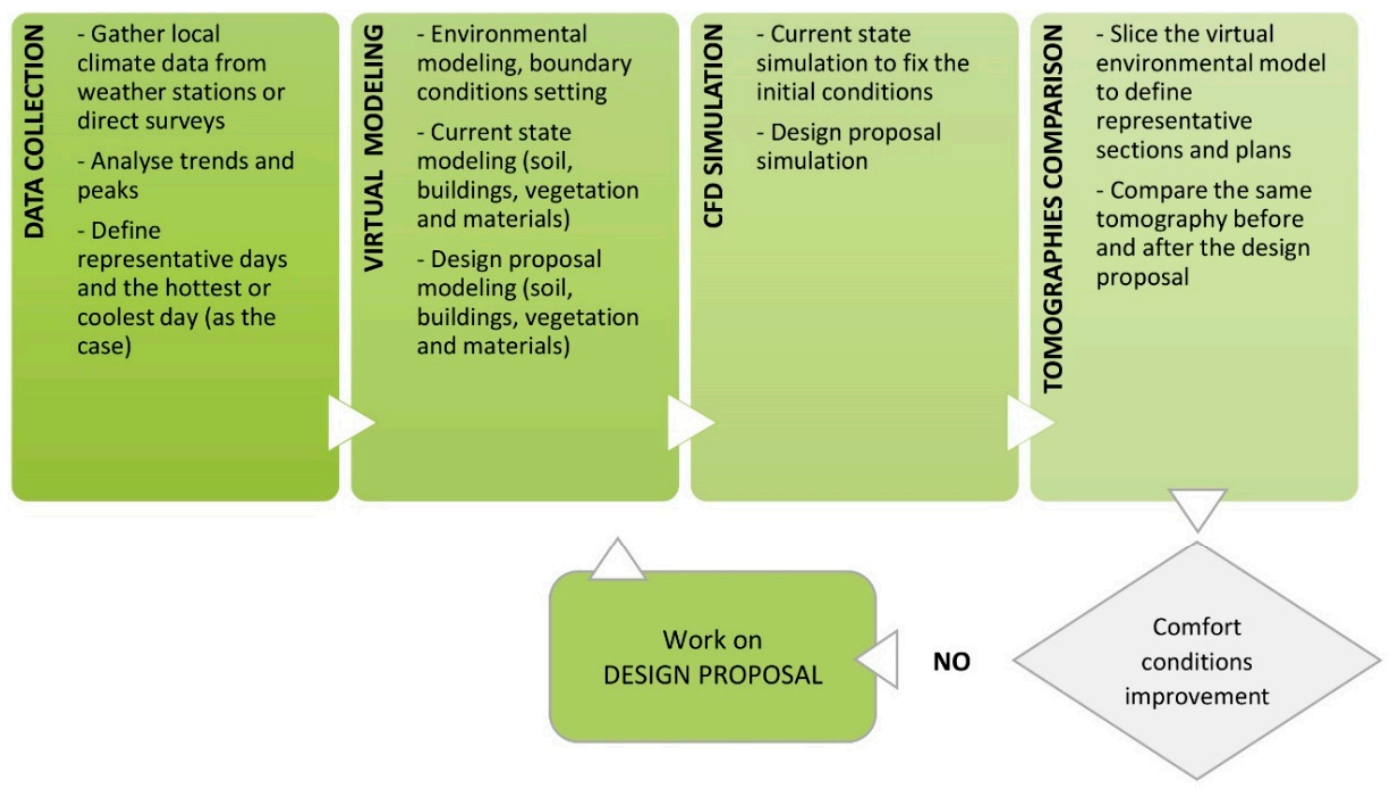

YES

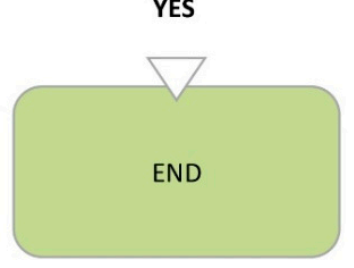

Figure 3. Tomographic environmental section (TENS) workflow.

Thermographic assessment made using this CFD software allows environmental conditions to be compared before and after intervention with respect to the climate values designed and the index of thermal comfort used. Several models have been developed to assess thermal comfort with respect to given climate conditions. These include the outdoor version of Fanger's predicted mean vote (PMV) model [17,18], the perceived temperature (PT) [19], and the universal thermal climate index (UTCI) [20]. In this case, the PMV, or Fanger index, was used. The PMV expresses an average score expected for the sensation of thermal well-being and allows for a subjective measure that does not depend on a single related environmental factor (temperature, humidity, wind speed, etc.), but rather on their combination (Equations (1)-(4)). The PMV index can be used to obtain another index, the predicted percentage of dissatisfied (PPD), which is a statistical quantity describing the amount of dissatisfied persons related to the corresponding comfort condition. To apply the PMV to outdoor conditions, Jendritzky [21] added complex outdoor radiation. The model, known as the Klima-Michel model (KMM), is an adaptation of Fanger's model (Equation (5)), with the inclusion of short-wave radiation in the mean radiant temperature.

$$
\begin{aligned}
\mathrm{PMV}=[0.303 . & \operatorname{Exp}(-0.036 \cdot M)+0.028] \\
& \cdot\left\{(M-W)-3.05 \times 10^{-3} \cdot\left[5733-6.99 \cdot(M-W)-p_{a}\right]-0.42\right. \\
& \cdot[(M-W)-58.15]-1.7 \times 10^{-5} \cdot M \cdot\left(5867-p_{a}\right)-0.0014 \cdot M \\
& \cdot\left(34-t_{a}\right)-3.96 \times 10^{-8} \cdot f_{c l} \cdot\left[\left(t_{c l}+273\right)^{4}-\left(\overline{t_{r}}+273\right)^{4}\right]-f_{c l} \cdot h_{c} \\
& \left.\cdot\left(t_{c l}-t_{a}\right)\right\}
\end{aligned}
$$


with:

$$
\begin{aligned}
& t_{c l}=35.7-0.028 \cdot(M-W)-I_{c l} \\
& \cdot\left\{3.96 \times 10^{-8} \cdot f_{c l} \cdot\left[\left(t_{c l}+273\right)^{4}-\left(\overline{t_{r}}+273\right)^{4}\right]+f_{c l} \cdot h_{c} \cdot\left(t_{c l}-t_{a}\right)\right\} \\
& h_{c}=\left\{\begin{array}{l}
2.38 \cdot\left|t_{c l}-t_{a}\right|^{0.25}, 2.38 \cdot\left|t_{c l}-t_{a}\right|^{0.25}>12.1 \cdot \sqrt{v_{a r}} \\
12.1 \cdot \sqrt{v_{a r}}, 2.38 \cdot\left|t_{c l}-t_{a}\right|^{0.25}<12.1 \cdot \sqrt{v_{a r}}
\end{array}\right. \\
& f_{c l}= \begin{cases}1.00+1.290 I_{c l}, & I_{c l} \leq 0.078 \mathrm{~m}^{2} \cdot \frac{K}{W} \\
1.05+0.645 I_{c l}, & I_{c l}>0.078 \mathrm{~m}^{2} \cdot \frac{K}{W}\end{cases}
\end{aligned}
$$

And for the PPD:

$$
\mathrm{PPD}=100-95 \cdot \operatorname{Exp}\left(-0.03353 \cdot \mathrm{PMV}^{4}-0.2179 \cdot \mathrm{PMV}^{2}\right)
$$

The minimum PPD is 5\%, even when PMV is zero.

where

$M \quad$ Metabolic rate $\frac{\mathrm{W}}{\mathrm{m}^{2}}$

$W \quad$ Effective mechanical power $\frac{W}{\mathrm{~m}^{2}}$

$I_{c l} \quad$ Clothing insulation $\frac{\mathrm{m}^{2} \cdot \mathrm{K}}{\mathrm{W}}$

$\overline{t_{r}} \quad$ Mean radiant temperature ${ }^{\circ} \mathrm{C}$

$t_{c l} \quad$ Clothing surface temperature ${ }^{\circ} \mathrm{C}$

$t_{a} \quad$ Air temperature ${ }^{\circ} \mathrm{C}$

$f_{c l} \quad$ Clothing surface-area factor

$v_{a r} \quad$ Relative air velocity $\frac{\mathrm{m}}{\mathrm{s}}$

$h_{c} \quad$ Convective heat transfer coefficient $\frac{\mathrm{W}}{\left(\mathrm{m}^{2} \cdot \mathrm{K}\right)}$

$p_{a} \quad$ Water vapor partial pressure $\mathrm{Pa}$

The pleasantness of environmental conditions for a sample of people is expressed by an average value of a vote given by the sample and is based on a "thermal sensation" scale. ASHRAE [22] proposes the following scale:

$+3=$ very hot

$+2=$ hot

$+1=$ slightly hot

$=$ comfortable

$-1=$ slightly cold

$-2=$ cold

$-3=$ very cold

\subsection{Site Climate and Simulation Scenarios}

Regarding the climate conditions in the area, Ascoli Piceno is characterized by a predominantly Mediterranean climate with an average temperature of $23.5^{\circ} \mathrm{C}$ in July, the hottest month of the year, and an average January temperature of $5.4^{\circ} \mathrm{C}$ (Figure 4). The climate is classified as $\mathrm{Cfc}$ according to the new Köppen and Geiger classification [23].

Two summer scenarios were considered as boundary conditions, that is, the climate/ environmental conditions of two specific days identified within the last decade.

In the first scenario, the representative day (Tirabassi and Nassetti) [24] for temperature was extracted from the historical period. Using data from 2008 to 2013 from the Assam meterological station [25], the representative day, 9 June 2010, was determined via statistical analysis. The representative day technique [26] yields a characteristic summer meteorological scenario (Figure 5) using actual data from days in the period. This technique involves minimizing the sum of the mean-square differences between the monitored quantities averaged within each hour and the same quantities for all other days at the same hour. Mathematically, this is expressed as Equation (6), where 
$N$ is the number of days in the time period considered and $c_{k i}$ is the meteorological data of the $i$ th day at the $k$ th hour.

$$
A_{i j}=\sum_{1}^{24}\left(c_{k i}-c_{k j}\right)^{2}, \quad i, j=1,2, \ldots \ldots N
$$

The most unfavorable day was chosen for the second scenario. This was identified as 14 August 2003, the hottest day ever recorded in Ascoli Piceno (Figure 6).

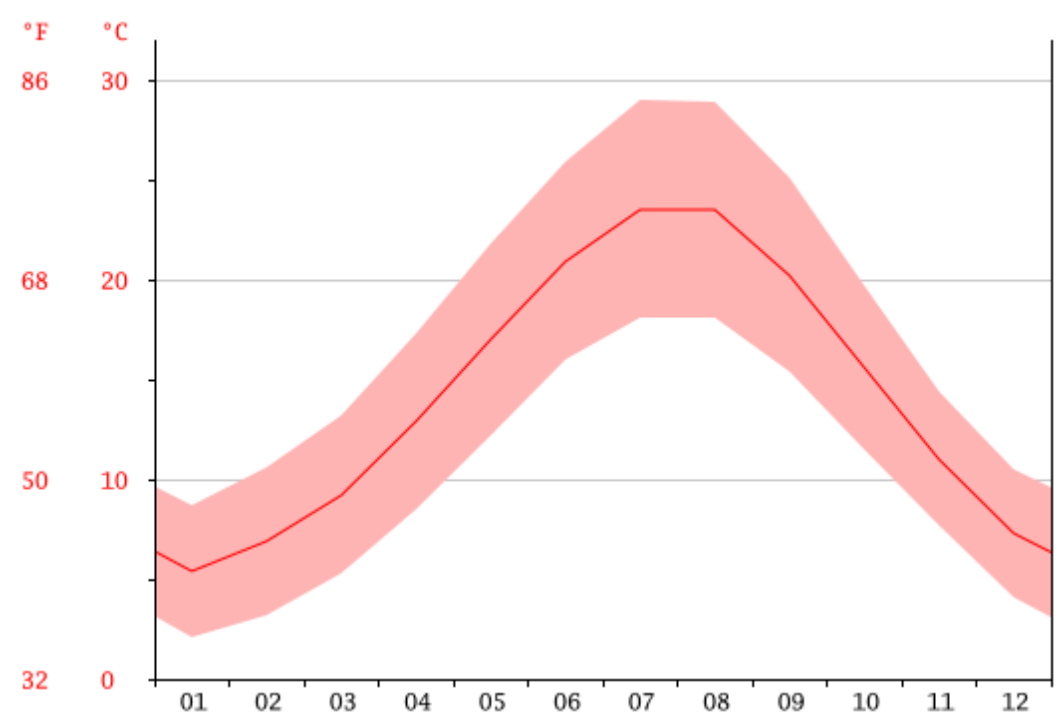

Figure 4. Ascoli Piceno average monthly temperatures.

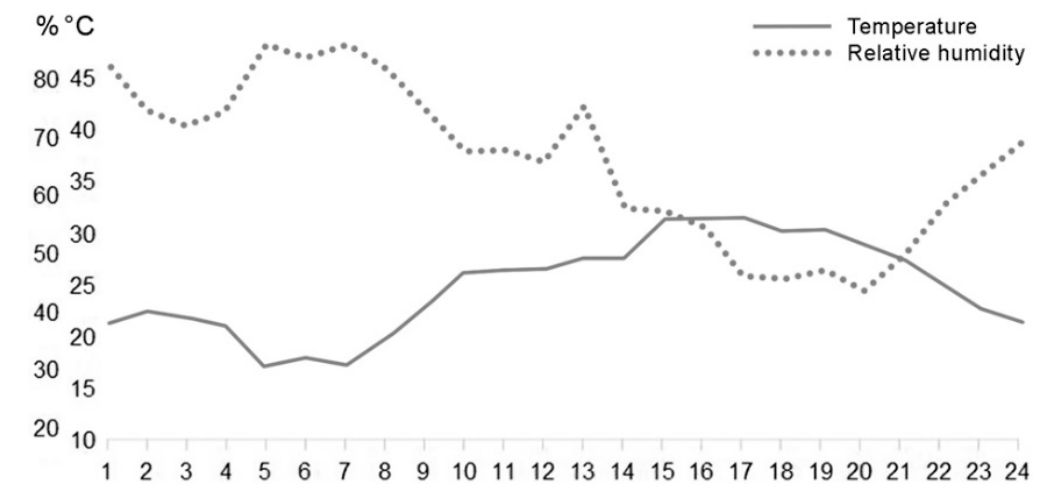

Figure 5. Climate data-Representative day.

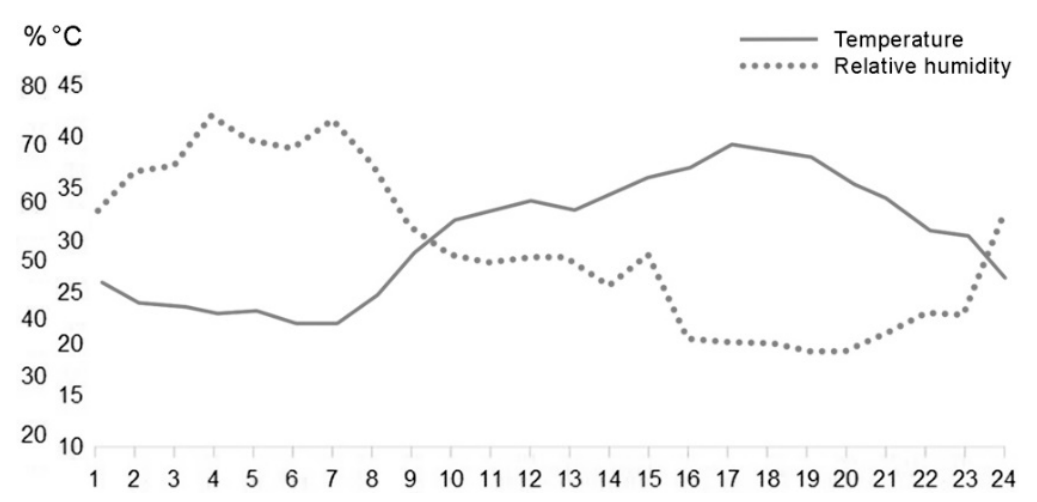

Figure 6. Climate data-Hottest day. 
The two days were simulated both for the current state and for the new design proposed. The input values for the thermal fluid dynamic simulations are indicated in Figure 7 and represent the initial and boundary conditions of the areas analyzed.

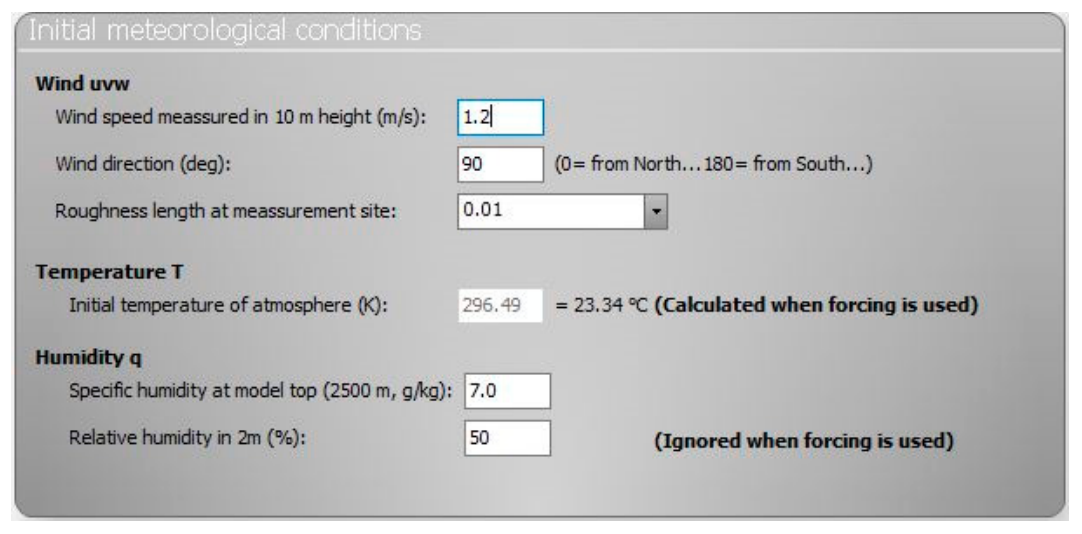

Figure 7. ENVI-met boundary conditions.

\subsection{Case Studies}

The effect of mitigating the UHI was evaluated by intervening on some chosen parts of the city of Ascoli Piceno with suitable devices aimed at lowering local temperatures and increasing wind flow. Four peripheral areas were chosen that were interesting from an urban-planning point of view and in which the thermal environment, by analyzing the UHI, was particularly uncomfortable. Of the four case studies, the first three consist of design proposals for future interventions, while the fourth has already been realized.

The first area is a natural terrace located next to the bus station. Multi-floor buildings tower over the area on two sides and the steep embankment of the Castellano River runs along the south side. Although dense vegetation covers the north side of the river, the paved square is one of the hottest places in the city. This is due primarily to its continuous exposure to sunlight and to the heat island generated around the nearby buildings, which is caused by the total lack of ventilation.

The same method was applied to another three very similar cases situated at the edges of the historical city center and closely connected to the river system. The various positions and uses of public spaces required different means of intervention, but thanks to the TENS method, it is possible to see an improvement in outdoor comfort during the summer and a positive mitigating influence in the microclimate of the city center.

One of these cases was the renovation of the ancient mill (Ex Società Impianti Materiali Elettrici (S.I.M.E.)) on the left bank of the Castellano River to the east of the historical center. Built in 1610, it was continually and radically modified over the centuries until it was completely transformed into an industrial building on the edge of the historical center in the early twentieth century. The goal of the proposal consists in rethinking not only the architecture, but also the urban area that connects the city to the river.

The third project verified using the TENS method is the design for a new construction on the north bank next to the medieval Porta Solestà bridge (Ascoli Piceno, Italy) that allows access to the historical center. The building is partially underground, with the main façade facing south and a green covering that becomes an extension of the public space. There is also a panoramic view of the city. In this case as well, maximum use is made of green areas and deciduous trees in synergy with passive control systems and humidity regulation.

The last case is a residential area to the west of the city center where a recent intervention for urban regeneration made by the city addressed the dismantling of the old shooting range by restoring the land and razing the main building. The open area is now used as a green public area with sports fields 
and a small playground. Since this was the only case already realized, the TENS method was useful for verifying the effective improvement of the microclimate conditions compared to the previous state.

\section{Results}

Up to now, territorial policies have focused on building-oriented theories centering on urban policies that consider neither the urban size nor the importance of open spaces within the overall balance of quality. They also overlook the role of space as a filter between interior and exterior [27]. These elements, however, do play a vital role in thermally mitigating the environmental conditions between buildings and the urban space [28].

\subsection{Case Study No. 1-Bus Station}

In the first area analyzed, the design proposal entails substituting at least $50 \%$ of the current paving in the square with a green parterre. It also doubles the number of deciduous trees (Tilia platyphyllos) along the street. Finally, it foresees a system of tensile shading structures composed of three reflecting and thermally insulating sails with a high albedo to protect the central part of the square from solar radiation.

Not only does TENS analysis show that effective improvements to the design proposal can be made, an average decrease in temperature of $\Delta T=1.4^{\circ} \mathrm{C}$ can also be obtained for the representative day (Figure 8). A decrease of $\Delta T=1.2{ }^{\circ} \mathrm{C}$ can be achieved for the heat wave (hottest day; Figure 9).

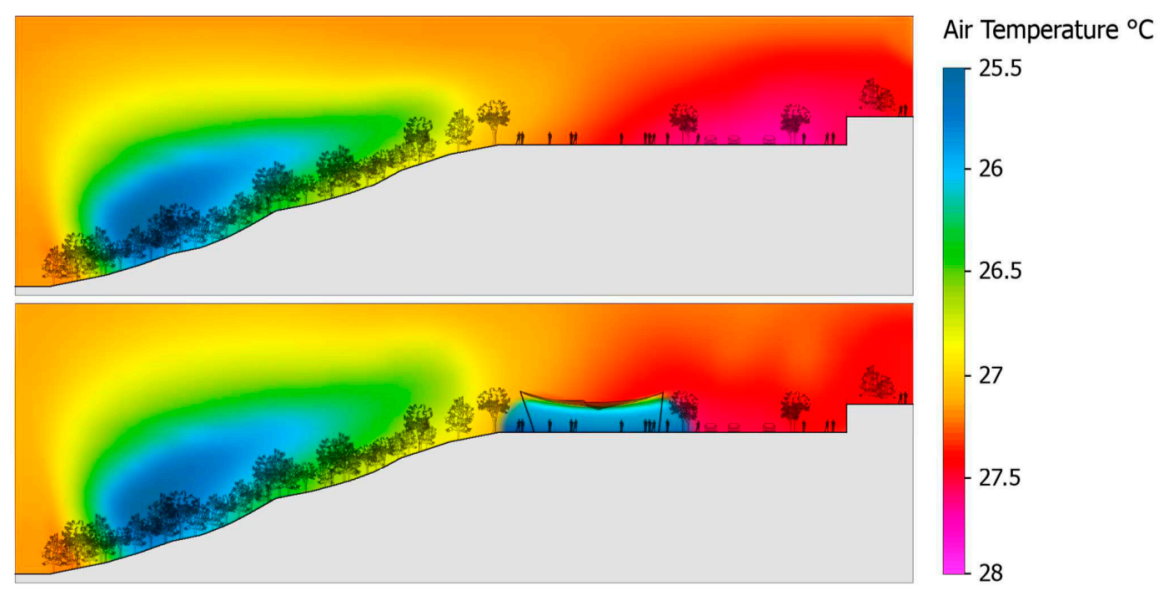

Figure 8. Bus station-Device mitigation during the representative day.

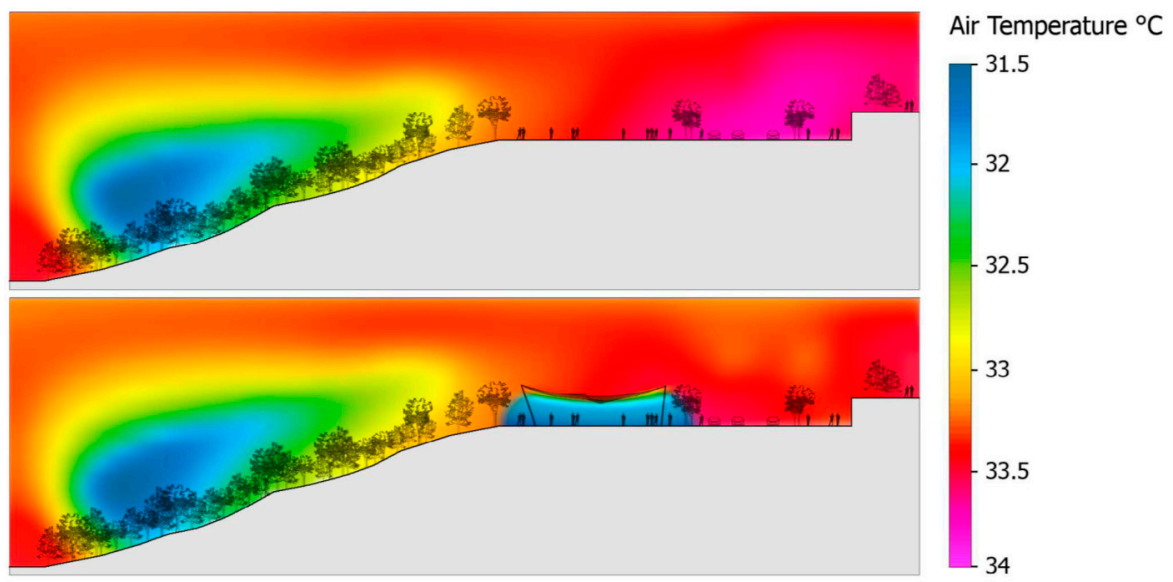

Figure 9. Bus station-Device mitigation during the hottest day. 
The PMV was calculated based on the effective use of the first case study. The site serves both as an entrance point to the city for visitors and tourists (the elevator rising from the covered parking below opens into the square) and as a hub for urban/interurban transport. Average body parameters were considered, with static clothing insulation (clo 0.5) and low metabolic work. With regard to the site's use, the midday hours are most important, as this is when maximum crowding and maximum average daily temperatures occur. The design solution confirms the predefined hypotheses, which are directed at lightening the thermal load on the surrounding buildings; the mitigating effects reach about $60 \mathrm{~m}$ from the square. For the representative day, an average change from about +2.3 for the current configuration to +0.3 is obtained for the project proposed (Figure 10). As a result of the design proposed, the PMV also changes from a state of hot discomfort $(+3)$ to an acceptably warm one $(+1.6)$ during the heat wave (Figure 11).

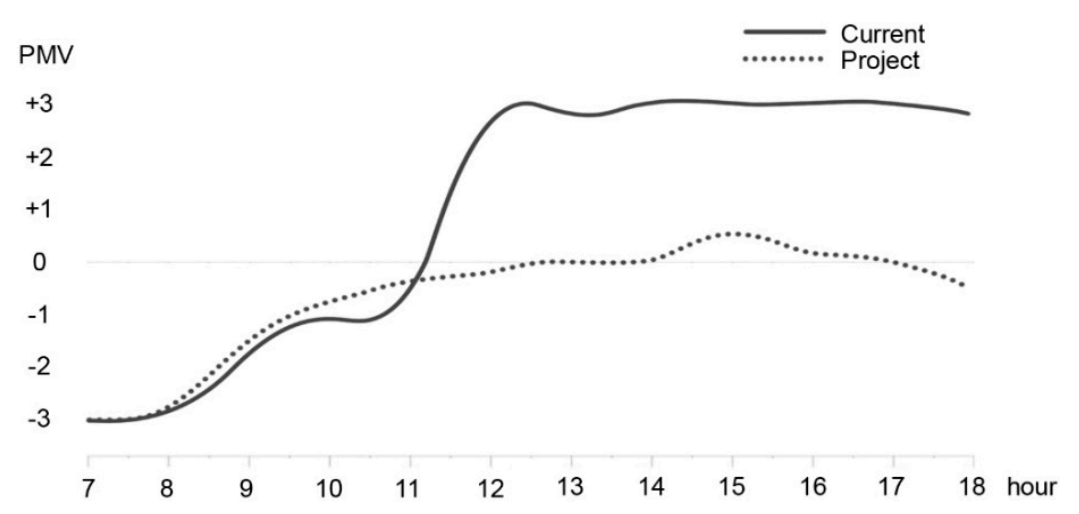

Figure 10. Predicted mean vote (PMV) trend-Representative day.

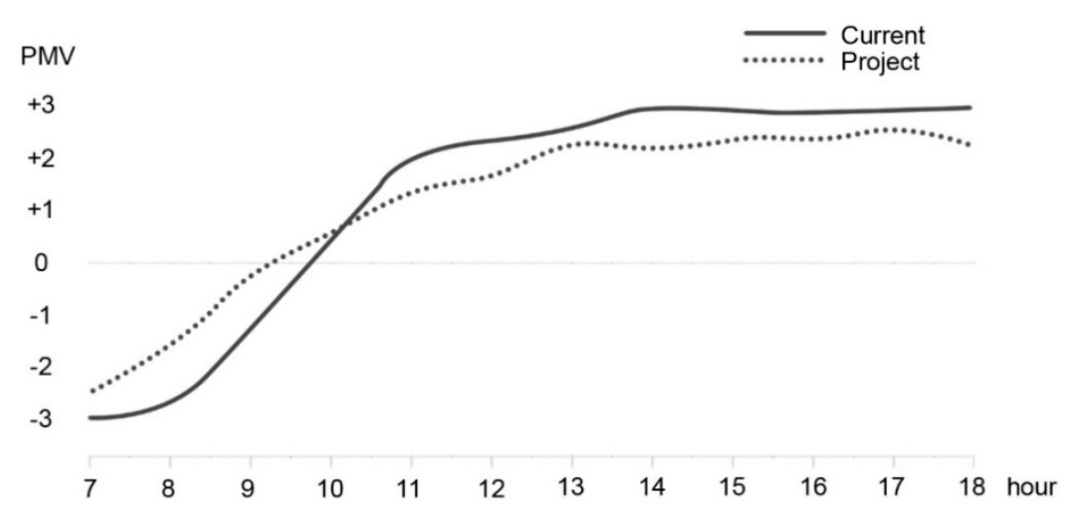

Figure 11. PMV trend-Hottest day.

TENS analysis highlights the positive role that vegetation plays in absorbing and mitigating heat. The greenery and its placement in the area must be chosen appropriately, and the tomographic cross-sections show how they are effective only if the tree shading provides continuous coverage. It is advantageous that tall broadleaf deciduous trees with abundant foliage are preferred in urban contexts, since they are also entirely environmentally friendly and naturally adapt to the seasons. Further benefits of the design proposal in thermo-regulating the urban environment include the light structures. The cross-sections demonstrate the importance of the sails: not only do they directly block direct solar radiation, they also work indirectly for the low release of heat into the nearby shaded pavement. The screening, reflecting, and insulating properties of the adjustable shade system contribute to outdoor comfort by guaranteeing significant protection from solar rays and pavement overheating. The result is PMV values in line with summer trends, even during heat waves, despite some small variations (Figure 12). 

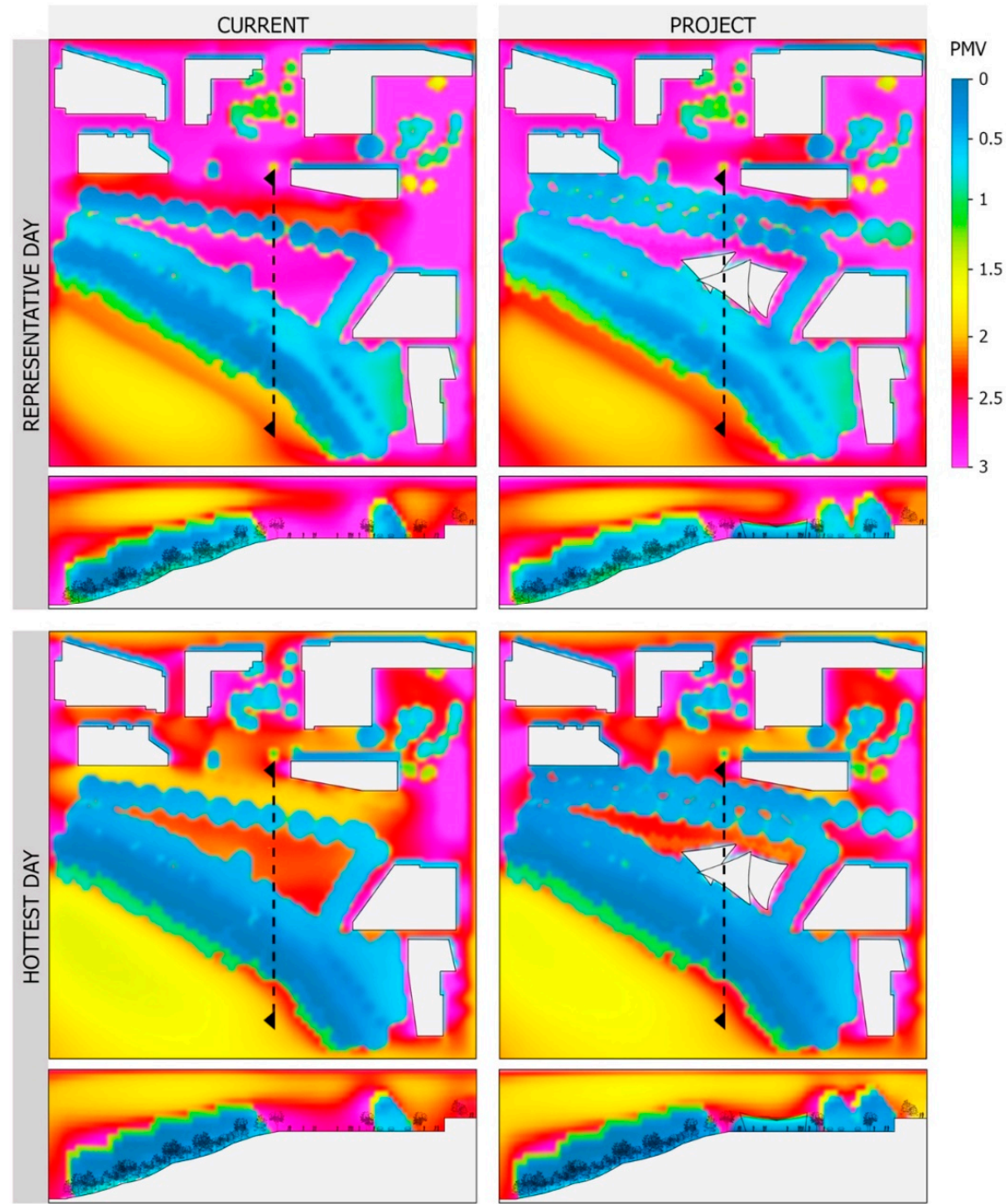

Figure 12. Bus station-PMV tomographies, plans and sections.

\subsection{Case Study No. 2-Ex S.I.M.E.}

For the other areas of intervention (areas no. 2, no. 3 and no. 4), the projects result in a local decrease in temperature of $0.5{ }^{\circ} \mathrm{C}$ during the heat wave. The zone of the Ex S.I.M.E. mill on the left bank of the Castellano River (Figure 13) registered an average gain of about one point on the PMV scale (from +2.8 to +1.9 , checkpoint on the main street, Figure 14).

The building's functional restoration is integrated with a careful design for environmental comfort, i.e., energy-efficient architecture that is sustainable and climatically responsive. The study entails vertical connections to overcome the steepness of the embankment, a bridge-square to reconnect the two banks of the Castellano River and host summer events, and the transformation of internal spaces into public places for use during the winter. The entire reinforced-concrete structure is thermally insulated and the south façades are equipped with fixed solar screens serving as a passive element. The result is an open but covered building where the river vegetation enters and follows the vertical connections, especially in the central hall. This is designed as a solar chimney to let in fresh air from the northern sides, using ascending fluxes to extract hot air during the summer season, or using it as a greenhouse during the winter months if the upper openings are closed. Exterior surfaces are treated with highly reflective white paint to create a cool roof. In addition, the rooftop terrace is covered with a high-tech shading fabric. Great attention was given to the external spaces and to mitigating summer heat. The bridge-square is studied to create a ground effect (thanks to the flat surface below 
and the wrinkled upper surface), which amplifies the flow of air within the gorge and allows greater dissipation of summer heat. Beyond integrating the vegetation and carefully using high-emissivity, highly reflective materials $(\varepsilon=0.87$; SRI $=82 \%)$ for the pavement, the square has water atomizers integrated in the lighting system. These are operational during the hottest days in order to cool the sunlit surfaces and increase the humidity in the air.

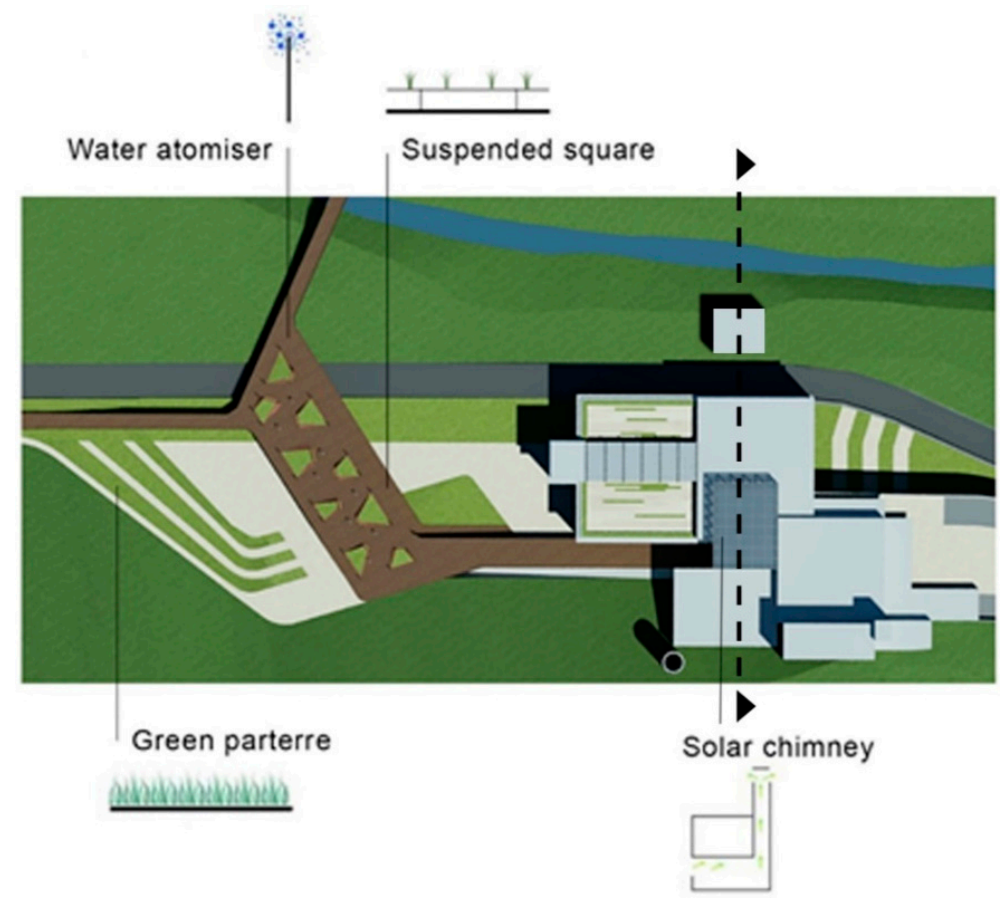

Figure 13. Case study no. 2, Ex S.I.M.E.

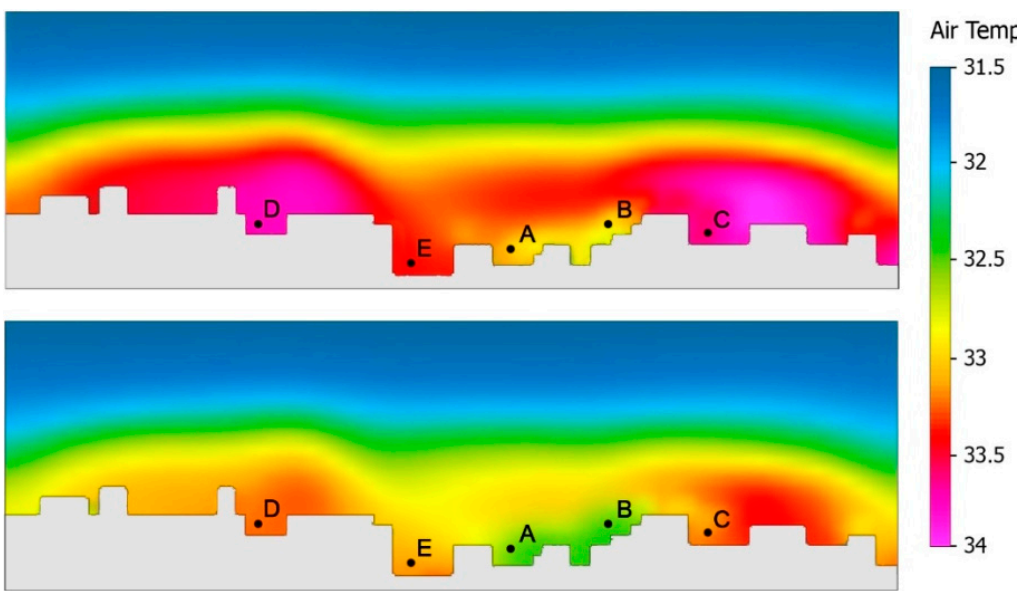

Figure 14. Ex S.I.M.E.- Temperature cross-section tomographies. Before intervention at the top, after intervention on the bottom (see Table 1).

Table 1. Ex S.I.M.E.-Temperature $\left({ }^{\circ} \mathrm{C}\right)$ before and after.

\begin{tabular}{cccccc}
\hline Checkpoint & A & B & C & D & E \\
\hline Before & 32.7 & 32.7 & 33.6 & 33.9 & 33.4 \\
After & 32.5 & 32.5 & 33.2 & 33.1 & 33.2 \\
\hline
\end{tabular}

Notes: A: External square; B: Main building; C: Corso Mazzini; D: Carbon; E: Castellano riverbed. 


\subsection{Case Study No. 3-Porta Solestà}

The third project verified using the TENS method is a new building designed for the north embankment of the Tronto River next to the medieval bridge which provides access to the historic center (Porta Solestà bridge). The building's main façade faces south and the green roof becomes an extension of public space with a panoramic view towards the city. Again, the massive use of green areas and deciduous planting is clear, which, along with the use of convective currents triggered by passive outdoor solar chimneys (Figure 15), guarantee an optimal level of comfort, notably affecting the entire surrounding built area, as shown in Figure 16. The tall chimneys towering over the treetops increase the thermal gradient between the vegetation-shaded ground and the top, which is heated by the Sun. Water atomizers and public benches are dispersed throughout the area, with the aim of creating several comfortable thermogeometric bubbles where people can enjoy the outdoor summer life.

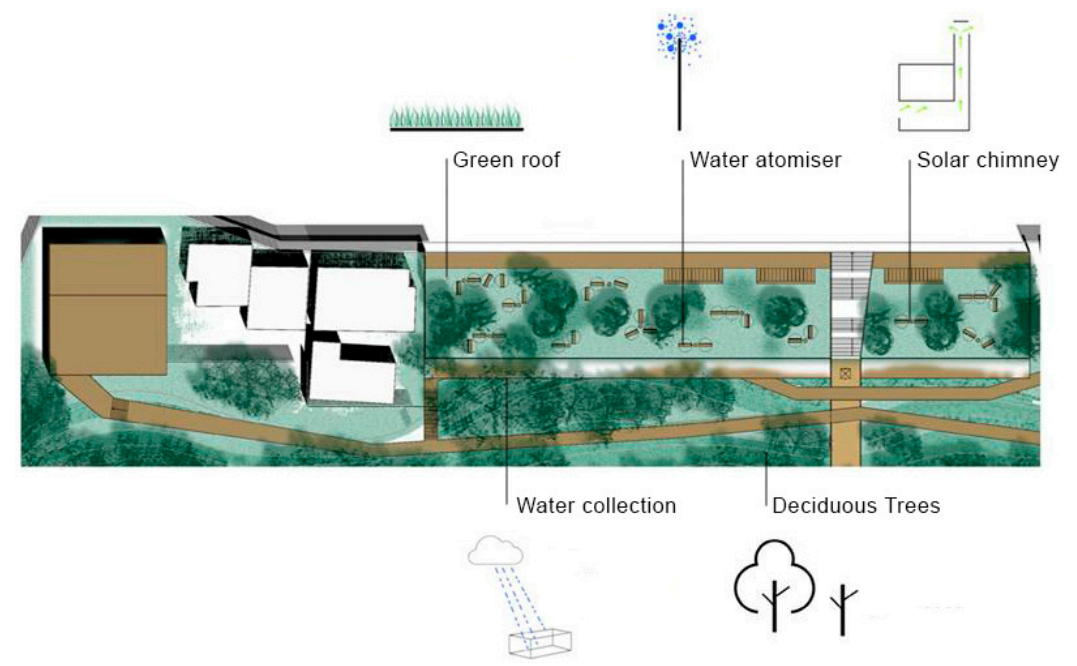

Figure 15. Case study no. 3, Porta Solestà.

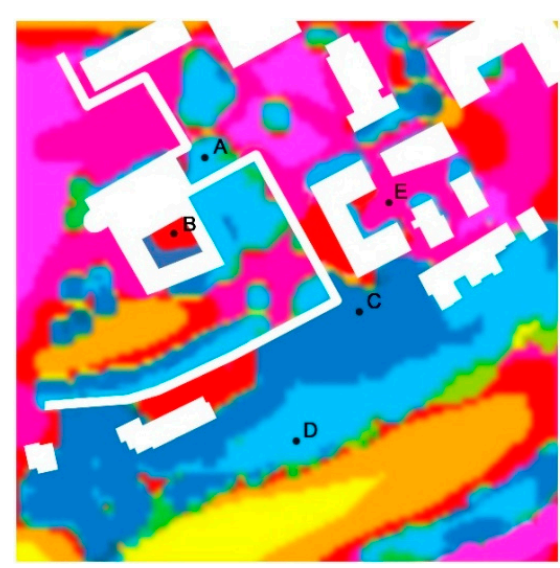

(a)

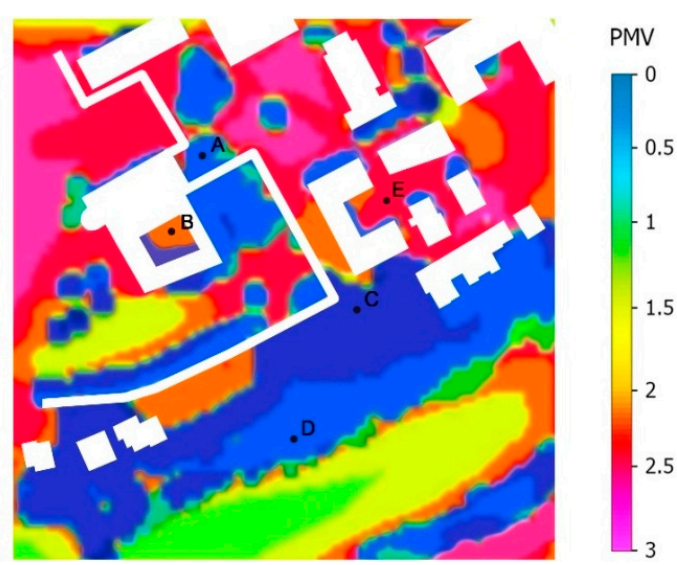

(b)

Figure 16. Porta Solestà-PMV tomographies. (a) Before intervention; (b) after intervention (see Table 2).

Table 2. Porta Solestà-PMV before and after.

\begin{tabular}{cccccc}
\hline Checkpoint & A & B & C & D & E \\
\hline Before & 0.7 & 2.4 & 0 & 0.7 & 3 \\
After & 0 & 1.6 & 1.3 & 1.6 & 1.2
\end{tabular}

Notes: A: Square; B: Cloister; C: San Serafino intersection; D: River bank; E: Building courtyard. 


\subsection{Case Study No. 4-Ex Tiro a Segno}

With respect to the fourth residential area of intervention, "Ex Tiro a Segno", to the west of the center of Ascoli Piceno, a recent urban renovation project involved the removal of the old shooting range, cleaning up the soil, and demolishing the main building. The freed area was reallocated by the city for a public garden and sports fields. Being the only case study already realized, the TENS method was useful in verifying the effective improvement of microclimate conditions over the previous situation.

There are rather small changes in the PMV (from +1.2 to +0.9 ) due to a very sparse urban fabric, with buildings that respect different zoning standards, i.e., working-class housing with three floors, wide courtyards, and a larger distance between buildings. In the second place, the use of the area has not changed; the previous green space was only remodeled and readapted for public use that was more appropriate for the needs of the neighborhood, without the use of more incisive microclimate mitigation systems (Figure 17).

These results show how (environmental) CFD tools, tomographic slicing, and the ability to apply different boundary conditions can be used to obtain a high accuracy of such considerations and the data to support them.

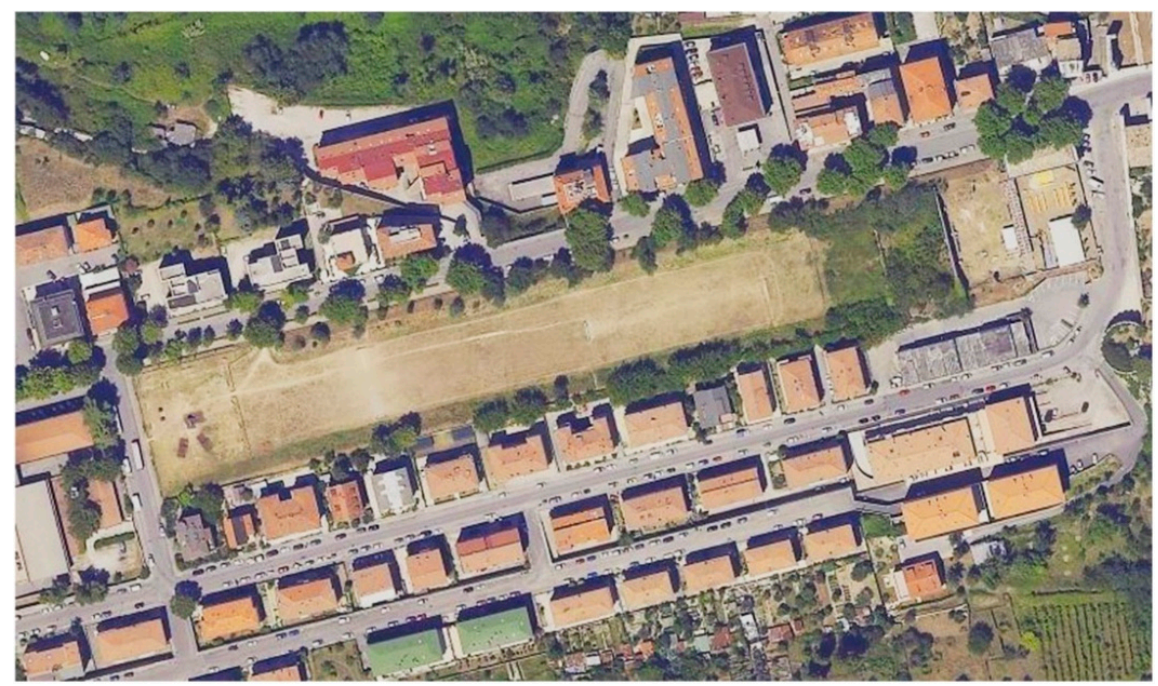

(a)

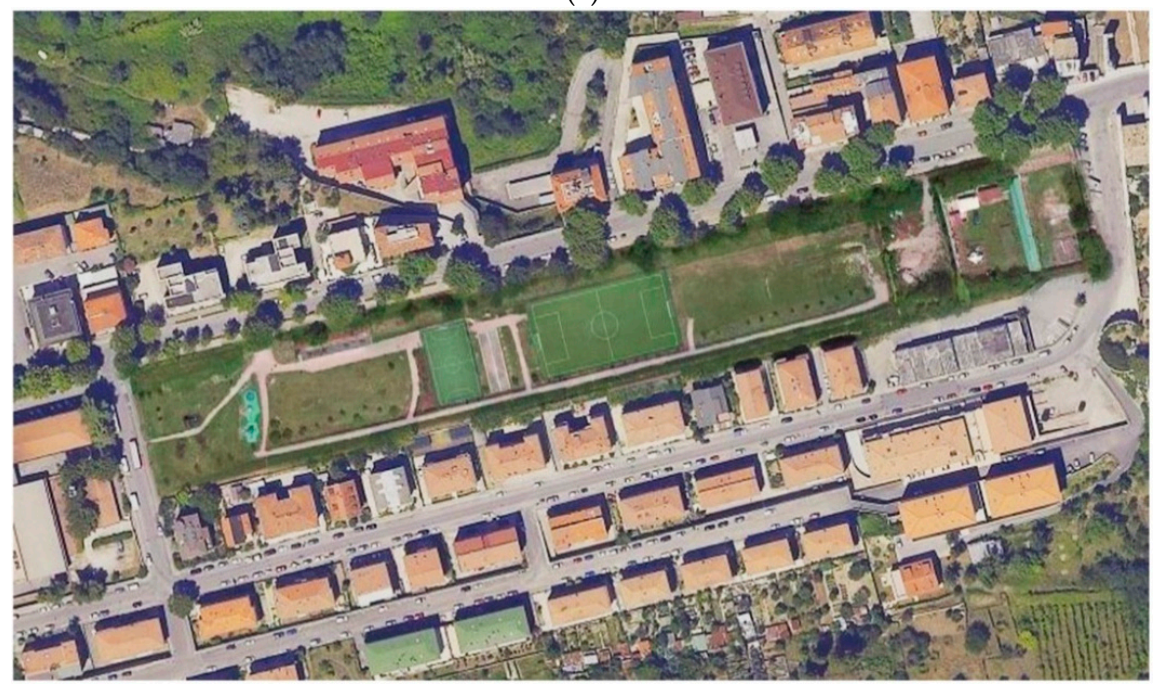

(b)

Figure 17. Ex Tiro a Segno. Before intervention at the top (a) and after intervention on the bottom (b). 


\section{Discussion}

Today, design on the urban scale, i.e., a city or collection of small centers that form a relatively recognizable and homogeneous system, does not seem possible without considering climate changes and the transformations that open spaces should undergo to make them useable, livable, and comfortable.

The most advanced position in urban planning today is oriented around regeneration processes that start from the most fragmented, minute needs to create an enormously complex reality [29]. This way of thinking according to "systems" with different components should respond to the larger objectives that are now unavoidable within worldwide urban policies: reduction of temperatures in urban centers, reduction of consumption, use of renewable resources, lowering $\mathrm{CO}_{2}$ emissions, and reusing waste.

Following these indications for urban reconfiguration, the TENS method was introduced. This allows the contribution of the environmental design for the urban area to be evaluated thanks to the use of thermal fluid dynamics. Analyzing the urban context in multiple cross-sections allows a series of small interventions to be identified that can mitigate the evident heat island effect registered even in small historical Italian towns [30]. Careful analysis of thermal gradients and fluxes related to the distribution of wind fields allows the type and size of the urban intervention to be understood, along with its spatial position according to the means of "urban acupuncture." This means acting in a point-like but widespread way within the city without making large changes or distorting what already exists, but rather acting with circumspection according to a well-defined map of actions and reactions. A further fundamental aspect of this method consists in the continuous education of citizens, who become involved in the transformation through formulas that translate into concrete advantages for those applying them. Therefore, the full awareness of the existing relationships between the different social, economic, and cultural components of the urban context makes it possible for interests to interact, drawing enormously strong advantages.

This model is still current and used today, for example, to reiterate the need for working on the double micro/macroscale to regenerate the city. Manuel de Sola Morales [31], for instance, has progressed along the lines of Lerner, working on the urban fabric as a multi-themed path of interpretation and regeneration through acupuncture. The overall results of the TENS technique according to "urban acupuncture" are illustrated in Figure 18 and Table 3. An improvement in the urban comfort conditions can be seen, along with the relative mitigation of the overall UHI phenomenon. It is also necessary to apply this point-like procedure to the historical fabric in order to achieve greater thermal mitigation and improve thermal comfort.

Table 3. Historical center of Ascoli Piceno-Temperature $\left({ }^{\circ} \mathrm{C}\right)$ before and after.

\begin{tabular}{cccccc}
\hline Checkpoint & A & B & C & D & E \\
\hline Before & 33.5 & 33.5 & 31.6 & 33.5 & 31.5 \\
After & 32.4 & 32.4 & 31.3 & 32.3 & 31.3 \\
\hline
\end{tabular}

Notes: A: Piazza del Popolo; B: Piazza Arringo; C: Piazza Ventidio Basso; D: Piazza San Tommaso; E: Colucci. 

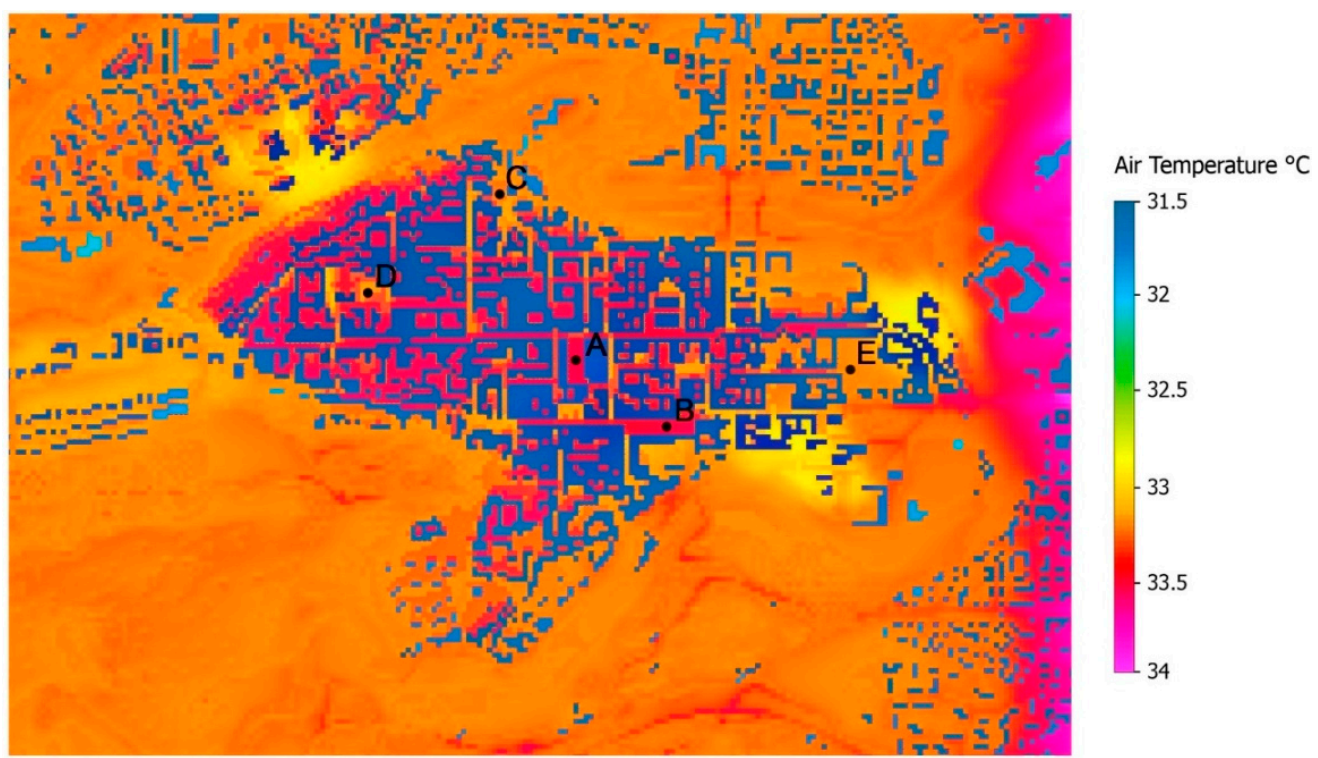

(a)

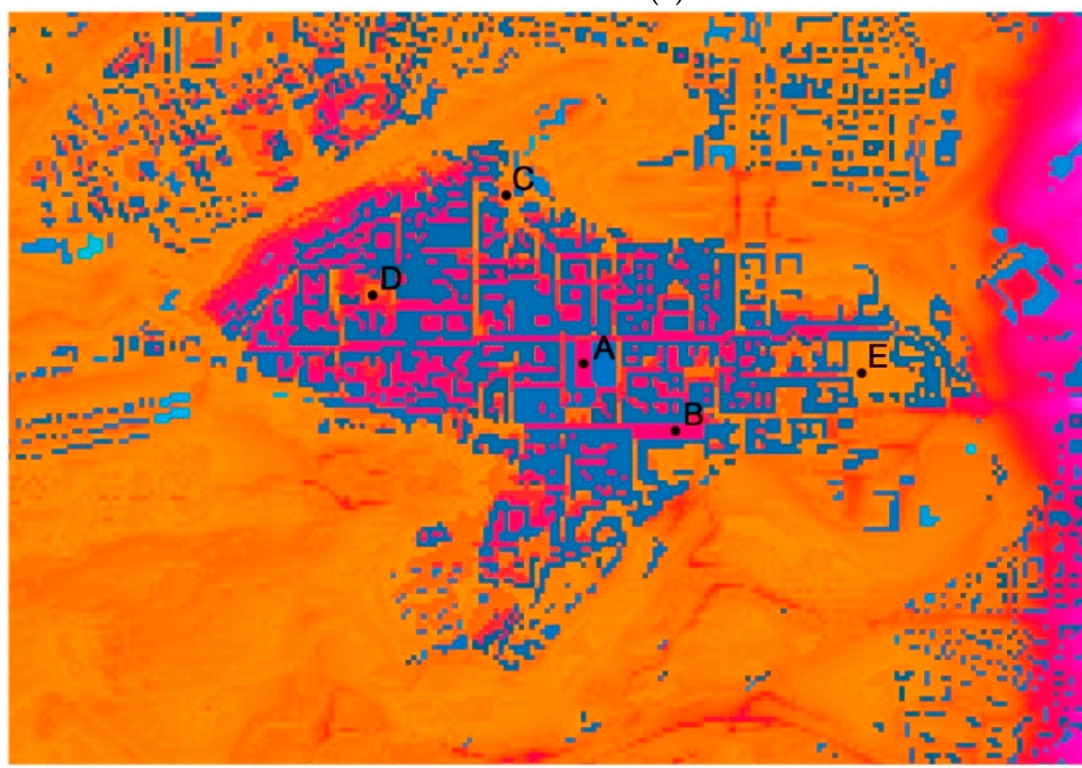

Air Temperature ${ }^{\circ} \mathrm{C}$

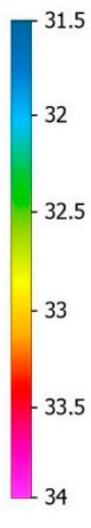

(b)

Figure 18. Temperature tomographies before and after intervention, in the whole city of Ascoli Piceno (before-intervention temperatures at the top (a) and after-intervention temperatures on the bottom (b)).

\section{Conclusions}

The TENS methodology is a powerful tool for studying the effects of the microclimate on the larger city, even during severe events, as well as the conformation of outdoor urban spaces. It may be used by designers in the early stages to assess different strategies to incorporate comfort requirements in architectural projects. Following the principles of urban acupuncture, the first principle to be stated is the "determination of sensitive points." This implies the application of urban acupuncture to determine the location of sensitive points (the hottest one, the most uncomfortable one). Although these are only initial results, they illustrate the innovative potential of TENS to investigate the small-scale design of open spaces and their effects on the wider urban scale. Users therefore become dynamic, reactive elements in the design process through their direct interaction with the different dynamic elements that contribute to defining environmental comfort. A prominent feature of TENS interventions is that they are small in scale, so that with small "pinpricks," large impacts can be obtained. 
This method therefore stands in stark contrast to the one usually applied to the climate design of buildings, which is generally static with respect to the building elements and material characteristics. In case studies presented here, the series of cross sections are used to establish different levels of comfort and suggest possible design corrections to obtain the best level of comfort suitable for the specific function of the site (for example, as a bus stop, refreshment area, etc.), which are also considered to be non-static. The functions may also be oriented to echo the natural characteristics of the area and to define its character, whether it is permanent, seasonal, or temporary. The initial experimentation in this study shows how different hypotheses can be designed and how their efficacy can be immediately verified. This work represents just the first application to the historical center of the city of Ascoli Piceno, where small, quick interventions are welcome. These small interventions can, however, have a catalytic effect in improving the thermal comfort and livability of the surroundings in order to enhance the microclimate in the city. There is, however, still a need for further investigation to check whether this methodology can lead to measures to mitigate the UHI phenomenon. The replication of these results in different fields of application will further validate the method for use by designers and city administrators.

Author Contributions: Maria Federica Ottone and Roberta Cocci Grifoni assessed the microclimate acupuncture strategies. Maria Federica Ottone and Enrico Prenna analyzed and designed the cases studies Roberta Cocci Grifoni analyzed the data and ran simulations using the CFD tool.

Conflicts of Interest: The authors declare no conflict of interest.

\section{References}

1. IPCC Climate Change 2014: Synthesis Report; Core Writing Team, Pachauri, R.K., Meyer, L., Eds.; IPCC: Geneva, Switzerland, 2014.

2. International Energy Agency. International Energy Agency 2014 Annual Report. 2015. Available online: https://www.iea.org/publications/freepublications/publication/2014_IEA_AnnualReport.pdf (accessed on 22 December 2016).

3. Baynes, T.; Bai, X.M. Trajectories of Change: Melbourne's Population, Urban Development, Energy Supply and Use 1960-2006; GEA Working Paper; International Institute for Applied Systems Analysis (IIASA): Laxenburg, Austria, 2009.

4. Bai, X. Integrating Global Environmental Concerns into Urban Management: The Scale and Readiness Arguments. J. Ind. Ecol. 2007, 11, 15-29. [CrossRef]

5. Lerner, J. Urban Acupuncture; Island Press: Washington, DC, USA, 2014.

6. Secchi, B. La città dei Ricchi e la Città dei Proveri; Laterza: Bari, Italy, 2013.

7. Piano, R. Report del G124-2013/2014; Il sole 24 ore; Gruppo 24 ORE: Milan, Italy, 2014.

8. Latini, G.; Cocci Grifoni, R.; Tascini, S. Thermal comfort and microclimates in open spaces. In Proceedings of the Thermal Performance of the Exterior Envelopes of Whole Buildings-11th International Conference, Clearwater Beach, FL, USA, 5-9 December 2010.

9. Ottone, M.F.; Grifoni, R.C. Environmental cross sectional tomography: A new approach to design and planning. In Proceedings of the 28th International PLEA Conference on Sustainable Architecture + Urban Design: Opportunities, Limits and Needs-Towards an Environmentally Responsible Architecture, PLEA 2012, Lima, Peru, 7-9 November 2012; p. 6.

10. Petrucci, E.; Leuzzi, A.G.; Lapucci, D.; Prenna, E. Energy performance planning in historical city centers through a "Geocluster" approach. In Proceedings of the Cultural Heritage International Conference (HERU 2015), Zagreb, Croatia, 22-23 October 2015.

11. Salata, F.; Golasi, I.; Vollaro, E.L.; Bisegna, F.; Nardecchia, F.; Coppi, M.; Gugliermetti, F.; Vollaro, A.L. Evaluation of different urban microclimate mitigation strategies through a PMV analysis. Sustainability 2005, 7, 9012-9030. [CrossRef]

12. Maciel, C.R.; Kolokotroni, M.; Nogueira, M.C.J.A.; Giridharan, R.; Watkins, R. The impact of surfacecharacteristics on ambient temperature at urban micro scale: Comparative field study in two climates. Int. J. Low-Carbon Technol. 2013, 10, 165-175. [CrossRef] 
13. Wong, N.H.; Chen, Y. Tropical Urban Heat Islands: Climate, Building and Greenery; Taylor and Francis: Abingdon, UK, 2009.

14. Musco, F.; Fregolent, L.; Ferro, D.; Magni, F.; Maragno, D.; Martinucci, D.; Fornaciari, G. Mitigation of and adaptation to UHI phenomena: The Padua case study. In Counteracting Urban Heat Island Effects in a Global Climate Change Scenario; Springer International Publishing: Gewerbestrasse, Switzerland, 2016.

15. Oke, T.R. Towards Better Scientific Communication in Urban Climate. Theor. Appl. Climatol. 2006, 84, 179-190. [CrossRef]

16. ENVI-met 4. A Holistic Microclimate Modelling System. Available online: http://www.model.envi-met. com/hg2e/doku.php (accessed on 22 December 2016).

17. Fanger, P.O. Thermal Comfort; Danish Technical Press: Copenhagen, Denmark, 1970.

18. Pickup, J.; De Dear, R.J. An outdoor thermal comfort index (OUT_SET ${ }^{*}$-Part I-The model and its assumptions. In Proceedings of the 15th International Congress of Biometeorology and International Conference on Urban Climatology, Sydney, Australia, 8-12 November 1999.

19. Jendritzky, G.; Staiger, H.; Bucher, K.; Graetz, A.; Laschewski, G. The perceived temperature: The method of the Deutscher Wetterdienst for the assessment of cold stress and heat load for the human body. In Proceedings of the Internet Workshop on Windchill, Toronto, ON, Canada, 3-7 April 2000.

20. Jendritzky, G.; Maarouf, A.; Staiger, H. Looking for a universal thermal climate index UTCI for outdoor applications. In Proceedings of the Windsor-Conference on Thermal Standards, Windsor, UK, 5-8 April 2001.

21. Jendritzky, G.; Menz, G.; Schirmer, H.; Schmidt-Kessen, W. Methodology for a Spatially Referenced Assessment of the Thermal Component of the Human Bio-Climate (Etended Klima-Michel Model); Beiträge Academy Raumforsch Landesplanung: Hannover, Germany, 1990; Volume 114.

22. ASHRAE Standard 55. Thermal Environmental Conditions for Human Occupancy; ASHRAE: Atlanta, GA, USA, 2015.

23. Kottek, M.; Grieser, J.; Beck, C.; Rudolf, B.; Rubel, F. World map of the Köppen-Geiger climate classification updated. Meteorol. Z. 2006, 15, 259-263.

24. Tirabassi, T.; Nassetti, S. The representative day. Atmos. Environ. 1999, 33, 2427-2434. [CrossRef]

25. ASSAM. Servizio Agrometeorologico Regionale, Marche Region. Available online: http://meteo.regione. marche.it/ (accessed on 26 January 2015).

26. Cocci Grifoni, R.; Pierantozzi, M.; Tascini, S.; Passerini, G. Assessing the representativeness of thermal comfort in outdoor spaces. WIT Trans. Ecol. Environ. 2011, 155, 835-846.

27. Wiley, J. Philippe Rahm meteorological architecture. In AD Architectural Design; John Wiley \& Sons: London, UK, 2009; Volume 79.

28. Katzschner, L.; Mayer, H.; Drey, C.; Bruse, M. Strategies and concepts for thermal comfort discussions in urban planning to mitigate the impacts of climate extremes. In Proceedings of the Sun, Wind and Architecture-The 24th International Conference on Passive and Low Energy Architecture, PLEA 2007, National University of Singapore, Singapore, 22-24 November 2007; pp. 103-108.

29. Ganis, M.; Minnery, J.; Mateo-Babiano, I. Planning people-places: A small world network paradigm for masterplanning with people in mind. Environ. Plan. B Plan. Des. 2015, 43, 1075-1095. [CrossRef]

30. Ambrosini, D.; Galli, G.; Mancini, B.; Nardi, I.; Sfarra, S. Evaluating mitigation effects of urban heat islands in a historical small center with the ENVI-Met ${ }^{\circledR}$ climate model. Sustainability 2014, 6, 7013-7029. [CrossRef]

31. De Solà-Morales, M.; Frampton, K.; Ibelings, H. Matter of Things; NAi Publishers: Rotterdam, The Netherlands, 2008.

(C) 2017 by the authors. Licensee MDPI, Basel, Switzerland. This article is an open access article distributed under the terms and conditions of the Creative Commons Attribution (CC BY) license (http:/ / creativecommons.org/licenses/by/4.0/). 